\title{
A Laboratory and Field Study of Border Check Irrigation
}

\author{
N. Collis-George ${ }^{\mathrm{A}}$ and D. M. Freebairn ${ }^{\mathrm{B}}$ \\ A Department of Soil Science, University of Sydney, N.S.W. 2006. \\ ${ }^{\text {B }}$ Queensland Wheat Research Institute, Department of Primary Industries, Toowoomba, Q1d. 4350
}

\begin{abstract}
Field and laboratory results of infiltration advance are presented. They are compared with results from equations that derive from the Lewis-Milne equation after substitution of infiltration relations based on independently determined parameters obtained from infiltration experiments.

In the laboratory, change of slope, change of supply rate, prewetting of the surface, and restriction of vertical air escape were studied in various combinations for two homogeneous materials. Change of supply rate, $q$, affected the rate of advance, $x$, while change of slope and prewetting the surface had only second order effects with a change of $q$. Results are compared in terms of the ratio $x / q$. Agreement between theory and experimental results is good.

The effect of restriction of air escape vertically ahead of the wetting front was marked, even though the measured increase in air pressure was small, and effectively reduced the parameters, sorptivity and hydraulic conductivity.

An innovation is to introduce a further term-the 'instantaneous' crack-filling volume. This slightly modifies the equations used for homogeneous materials and provides very good descriptions of irrigation advance phenomena for a cracking grey clay, a duplex red-brown earth, and for laboratory simulated duplex profiles consisting of two thicknesses of coarse sand overlying fine sand.

The movement of water into the layered sand systems showed that infiltration is not entirely vertical as equired by the Lewis-Milne equation.

The implications of the experimental results and the use of infiltration-advance equations in studies of the irrigation of field soils are briefly discussed.
\end{abstract}

\section{Introduction}

Preliminary experiments using a simple flume were reported by Collis-George (1974). In essence these experiments suggested that irrigation advance for the materials studied obeyed the Lewis-Milne (1938) volume-balance equation. However, the infiltration-advance behaviour of some materials was best described by the substitution of the infiltration equation of Philip $i=S \sqrt{ } t+A t$ (applicable to short times) into the Lewis-Milne equation, whereas the behaviour of other materials required an infiltration equation that implied that steady-state infiltration behaviour dominated soon after irrigation had begun, i.e. when

$$
i=i_{0}+K t \text {, }
$$

where $i$ is the cumulative infiltration at time $t$;

$S$ is the sorptivity;

$A$ is an infiltration constant;

$K$ is the infiltration rate at steady state, i.e. the hydraulic conductivity of the transmission zone; 
$i_{0}$ is that part of the cumulative infiltration at long time attributable to capillary effects, i.e. the intercept at $t=0$ of a plot of those values of $i v . t$ when steady-state infiltration rate has been attained.

The present study uses a wider range of laboratory materials and a bigger and more robust flume that allows a better simulation of border check irrigation, and also examines the field behaviour of two soils. It confines itself to the first phase of border check irrigation, viz. the advance phase (Sakkas and Strelkoff 1974) and does not consider vertical or down-slope recession.

The purpose of the study is not only to gain more experience of the phenomena associated with infiltration advance, but also to test further the premise that predeterminable physically significant parameters can be used to predict field irrigation behaviour.

\section{Theory}

Lewis and Milne (1938) first proposed the volume-balance equation describing infiltration advance:

$$
q t=c x+\int_{0}^{t} i\left(t-t_{s}\right) x^{\prime}\left(t_{s}\right) \mathrm{d} t
$$

where $\quad q=$ flow rate per unit width;

$c=$ height of water ponded on the surface;

$x=$ advance at time $t$;

$i\left(t-t_{s}\right)=$ the cumulative infiltration at position $s$;

$x^{\prime}\left(t_{s}\right)=\mathrm{d} x / \mathrm{d} t$ at time $\left(t-t_{s}\right)$

$t_{s}=$ time at which $x\left(t_{s}\right)=s$.

To manipulate the equation, a relation for $i(t)$, the cumulative infiltration is required. Philip and Farrell (1964), followed by Asseed and Kirkham (1968) and Collis-George (1974), substituted various vertical infiltration equations into (1) before using the Faltung Theorem of the Laplace Transformation to produce infiltration-advance equations that can be tested experimentally.

These derivations assume amongst other things that flow of water in the soil is entirely vertical, an assumption that for some soil systems in the flume is demonstrably untrue.

In addition to the two infiltration equations considered earlier (Collis-George 1974), viz.,

$$
\begin{aligned}
& i=S \sqrt{ } t+A t \\
& i=i_{0}+K t
\end{aligned}
$$

modified equations are needed for materials that initially have large cracks which close quickly but in the initial wetting period store a volume of water $i_{i}$, viz.,

$$
\begin{aligned}
& i=i_{i}+S \sqrt{ } t+A t \\
& i=i_{i}+i_{0}+K t .
\end{aligned}
$$

The use of (2a) and (3a) implies that the time for storage in cracks is small compared with the time for appreciable infiltration due to the time sensitive terms.

In some materials the $A t$ term is relatively small and the relation

$$
i=i_{i}+S \sqrt{ } t
$$

satisfactorily describes cumulative infiltration over the times normally associated with field irrigation. 
As will be shown a cracking grey clay studied in this paper was satisfactorily described by (2b), whereas a duplex red-brown earth needed the use of equation (2a).

For soil systems with two layers, where the $K$ and $S$ of the upper layers are large compared with the lower layer values, the time taken to saturate the upper layer is relatively small. Consequently the same approximation can be made as for soils with cracks, and equations (2a) and (3a) can be used where $i_{i}$ is now the thickness of the upper layer multiplied by the change in volumetric moisture content. This approximation has been studied for two thicknesses of a coarse sand overlying a fine sand in the experimental flume.

$A$ and $K$ in principle can be derived from the manipulation of the cumulative infiltration data at short and long times respectively. In practice the accuracy at short times for many materials is such that $A$, which from theory is $\sim \frac{1}{3}$ saturated hydraulic conductivity (Philip 1957), cannot be determined reliably. In addition, infiltration behaviour is affected by the head of water, $c$. If therefore the meanings of $S$ and $A$ in (2) and (2a) are to be identical with those of the first two terms of the time expansion for vertical infiltration initially proposed by Philip (that is, derivable from the hydraulic conductivity-moisture content-moisture potential characteristics) further modification to (2) and (2a) must be made to allow for the thickness of water, $c$.

In this paper, for convenience, we propose firstly to determine the cumulative infiltration versus time relationship under heads which are the same as those to be used in the subsequent irrigation experiments, and secondly to fit the data to equations which have the form of (2a) and (3a) such that $A=K$. Under these circumstances, $K$ is not the saturated hydraulic conductivity but is the infiltration rate at long times, and $S$ is similar but not numerically identical with the sorptivity of Philip obtained more conventionally ( $S$ is here obtained from the short time data from the slope of $\left(i-K t-i_{i}\right)$ versus $\left.\sqrt{ } t\right)$.

With this procedure the values of $i_{i}, K=A, S$ and $i_{0}$, when substituted into equations ( $2 a$ ) and ( $3 a$ ), have allowed for the effect of the head, $c$, and the proposals of Parlange (1973) which correct for the effect of hydraulic head on infiltration and its subsequent modification of the solution to the Lewis-Milne equation can be avoided.

Using the Faltung Theorem, Philip and Farrell (1964) solved equation (1) for infiltration behaviour described by (2).

The same solution can be used for $(2 \mathrm{a})$, since $i_{i}$ does not vary with time and results in the first term in equation (1) becoming $\left(c+i_{i}\right) x$. The solution to (1) using (2a) and equating $A$ with $K$ becomes

$$
\frac{x}{q}=\frac{1}{K}\left[1-\frac{1}{\alpha^{*}-\beta^{*}}\left(\alpha^{*} \operatorname{erc} \beta^{*} \sqrt{ } \tau-\beta^{*} \operatorname{erc} \alpha^{*} \sqrt{ } \tau\right)\right],
$$

where $\alpha^{*}, \beta^{*}=1 \pm(1-\gamma)^{\frac{1}{2}}$;

$$
\begin{aligned}
& \gamma=\frac{16}{\pi} \frac{K\left(c+i_{i}\right)}{S^{2}} \\
& \tau=\frac{\pi S^{2} t}{16\left(c+i_{i}\right)^{2}}=\frac{K t}{\gamma\left(c+i_{i}\right)}
\end{aligned}
$$

and $\operatorname{erc} \eta=\exp \left(\eta^{2}\right) \operatorname{erfc} \eta$, a tabulated function. 
Similarly the solution to (1) using (3) given by Collis-George (1974) becomes

when (3a) is used.

$$
\frac{x}{q}=\frac{1}{K}\left(1-\exp \frac{-K t}{i_{i}+i_{0}+c}\right),
$$

For infiltration behaviour described by ( $2 b)$, the Faltung Theorem gives

$$
\frac{x}{q}=\frac{4\left(c+i_{i}\right)}{\pi S^{2}}\left[\frac{4 \sqrt{ } \tau}{\sqrt{\pi}}+\operatorname{erc} 2 \sqrt{ } \tau-1\right] .
$$

For soils with large 'instantaneous' storage $\left(c+i_{i}\right)$ is large compared with $S \sqrt{ } t$, hence $\tau$ is small up to several hours and (6) reduces to

$$
\frac{x}{q}=\frac{t}{\left(c+i_{i}\right)}\left[1-\frac{8 \sqrt{ } \tau}{3 \sqrt{ } \pi}+2 \tau-\ldots\right] .
$$

In such systems, initially there will be a linear advance with time down the border check. This yields values of $c+i_{i}$ that can be compared with direct measurements.

Equation (6a) is similar to the short term expansion of (4) given by equation (48) of Philip and Farrell (1964) replacing $c$ by $c+i_{i}$ and where the third term in the bracket has been modified to allow for $K$ in (2a).

\section{Experimental}

\section{Flume Experiments}

The flume was constructed with $12 \mathrm{~mm}$ thick acrylic retaining walls supported by an angle steel frame and was $3.66 \mathrm{~m}$ long, $0.91 \mathrm{~m}$ high and $0.02 \mathrm{~m}$ wide. The flume did not require any internal spacers or supports because of the external reinforcement.

Soil air pressure could be monitored during infiltration and the moisture content of the transmission zone could be determined at the end of an experiment via sample ports along the side of the flume. Slope could be varied from $0 \%$ to $2 \%$. Water was supplied from a pressurized Mariotte bottle which permitted a range of constant flow rates, $q$.

Depth of infiltration at various positions along the flume, advance of water down the flume, $x$, height of water on the surface, $c$, were observed as they varied with time, directly or photographically through the transparent walls of the flume.

In this paper the flume results from five variables are included, viz.: three porous systems including two-layer profiles; three slopes; three flow rates; two surface moisture conditions; and impeded versus unimpeded air escape from the base of the flume.

Table 1 summarizes the range of experimental conditions for all experiments. $c$, the depth of water, was not directly controlled but was a consequence of $q$, slope and surface conditions. For the flume experiments, $c$ was constant over the length and time of the advance. In the bays $c$ was distinctly deeper at the inlet end of the bay; average values for the main part of the run are given.

Air-dry porous material was poured into the flume while the flume was both tapped and vibrated. When a constant volume was obtained, after a further period of vibration, the surfaces was graded to produce a uniform constant slope.

Different flow rates were obtained using a fine metering valve in a constant pressure water supply line. Water was introduced via a stilling pond and weir. To study the effects of a change in the surface wetness a fine mist was sprayed on to the surface of the sand just prior to a run. 
Air escape was impeded by sealing the sampling ports and base of the model flume with petroleum jelly.

In this preliminary paper single, not replicated, experiments are considered because there was no ambiguity in the application of the quite dissimilar conditions of each variable, and major phenomenological differences only are being investigated at this stage.

Vertical infiltration characteristics of the laboratory materials were determined in $3.2 \mathrm{~cm}$ diameter columns with the same head, $c$, as obtained in the flume.

Table 1. Summary of experimental conditions

\begin{tabular}{|c|c|c|c|c|c|}
\hline Run & Material & $\begin{array}{c}q \\
\left(\mathrm{~cm}^{2} / \mathrm{min}\right)\end{array}$ & $\begin{array}{l}\text { Slope } \\
(\%)\end{array}$ & $\begin{array}{c}c \\
(\mathrm{~cm})\end{array}$ & Special features \\
\hline \multicolumn{6}{|c|}{ (a) For Flume } \\
\hline 1 & \multirow[t]{9}{*}{ G150 } & 0.034 & 0.4 & 0.2 & - \\
\hline 2 & & 0.014 & 0.4 & 0.2 & - \\
\hline 3 & & 0.013 & 1.0 & 0.1 & . - \\
\hline 4 & & 0.013 & 0 & 0.3 & - \\
\hline 5 & & 0.014 & 0.45 & 0.1 & Surface pre-wetted \\
\hline 6 & & 0.061 & 0.45 & 0.3 & - \\
\hline 7 & & 0.036 & 0.45 & 0.2 & 一 \\
\hline 8 & & 0.035 & 0.45 & $0.2\}$ & \multirow{2}{*}{ Impeded air escape } \\
\hline 9 & & 0.033 & 0.48 & $0.26\}$ & \\
\hline 10 & \multirow[t]{4}{*}{ Kraznozem } & 0.016 & 0.48 & $0 \cdot 1$ & $\longrightarrow$ \\
\hline 11 & & 0.032 & 0.48 & 0.2 & - \\
\hline 12 & & 0.062 & 0.48 & 0.26 & - \\
\hline 13 & & 0.031 & 0.48 & 0.2 & Impeded air escape \\
\hline 14 & $\begin{array}{l}15 \mathrm{~cm} \mathrm{G1} \\
\text { on } \mathrm{G} 150\end{array}$ & 0.034 & 0.48 & 0.22 & \\
\hline 15 & $\begin{array}{l}10 \mathrm{~cm} \mathrm{G1} \\
\text { on } \mathrm{G} 150\end{array}$ & 0.035 & 0.48 & 0.2 & \\
\hline \multicolumn{6}{|c|}{ (b) Field Results } \\
\hline 16 & Grey clay & 750 & 0.1 & $3 \cdot 8$ & Oat stubble 22.v.75 \\
\hline 17 & Red-brown & 930 & 0.25 & $4 \cdot 0$ & Lucerne $\quad 22$. iv.75 \\
\hline 18 & earth & 930 & 0.25 & $4 \cdot 0$ & Lucerne \\
\hline
\end{tabular}

\section{Field Experiments}

The trials were carried out on two sites at the New South Wales Department of Agriculture Research Station, Trangie:

(a) a red-brown earth with a surface texture of fine sandy clay. The irrigation bay for this soil was $30 \mathrm{~m}$ wide, $300 \mathrm{~m}$ long with a slope of $0.25 \%$ established under lucerne pasture;

(b) uniform grey clay with a self-mulching surface. The irrigation bay was $39 \mathrm{~m}$ wide, $270 \mathrm{~m}$ long with a slope of $0.1 \%$. At the time of irrigation, the surface was oat stubble with surface aggregates less than $2 \mathrm{~cm}$ in diameter.

Infiltration data were obtained using $30 \mathrm{~cm}$ diameter ring infiltrometers driven $80 \mathrm{~cm}$ into the soil. A constant head water supply was maintained for $24 \mathrm{~h}$ and cumulative infiltration with time was determined. The mean infiltration behaviour 
from 10 sites on each soil type was used in the theoretical predictions of infiltration advance.

The value of $c$ was determined in two ways:

(i) Directly at predetermined pegs over the length of the bay. Because of surface

Table 2. Properties of experimental materials

(a) Size distribution of sands and aggregates used in flume experiments:

G1 sand $\quad 0.50 / 0.15 \mathrm{~mm}$; mean diameter $0.24 \mathrm{~mm}$

G150 sand $0.15 / 0.035 \mathrm{~mm}$; mean diameter $0.078 \mathrm{~mm}$

Kraznozem $1.68 / 0.037 \mathrm{~mm}$; mean diameter $0.55 \mathrm{~mm}$

(b) Parameters for the materials used in the flume experiments:

\begin{tabular}{lccccrc}
\hline & $\begin{array}{c}\rho \\
\left(\mathrm{g} \mathrm{cm}^{-3}\right)\end{array}$ & $\begin{array}{c}K \\
\left(\mathrm{~cm} \mathrm{~min}^{-1}\right)\end{array}$ & $\begin{array}{c}S \\
\left(\mathrm{~cm} \mathrm{~min}^{-\frac{1}{2}}\right)\end{array}$ & $\begin{array}{c}i_{0} \\
(\mathrm{~cm})\end{array}$ & $\begin{array}{c}t_{\mathrm{c}} \\
(\mathrm{min})\end{array}$ & $\begin{array}{c}\Delta \theta_{\mathrm{v}} \\
\left(\mathrm{cm}^{3} \mathrm{~cm}^{-3}\right)\end{array}$ \\
\hline G1 sand & 1.60 & 2.10 & $\sim 6.00$ & $\sim 8.0$ & 1.9 & 0.40 \\
G150 sand & 1.60 & 0.21 & 1.47 & 9.0 & 37.5 & 0.40 \\
Kraznozem & 1.10 & 0.43 & 2.50 & 8.0 & 10.2 & 0.48
\end{tabular}

(c) $\%$ particle size analysis of flume and field soils:

\begin{tabular}{lccc}
\hline & $2-0.02 \mathrm{~mm}$ & $0.02-0.002 \mathrm{~mm}$ & $<0.002 \mathrm{~mm}$ \\
\hline $\begin{array}{l}\text { Kraznozem } \\
\text { Red-brown earth }\end{array}$ & 30 & 19 & 51 \\
$\quad 0-20 \mathrm{~cm}$ & 51.5 & 24.2 & $7 \cdot 2$ \\
$\quad 20-60 \mathrm{~cm}$ & $30 \cdot 7$ & $20 \cdot 8$ & $48 \cdot 5$ \\
Uniform grey clay & & & 52 \\
0-60 cm & 34 & 14 &
\end{tabular}

(d) Parameters determined using infiltrometers:

\begin{tabular}{lcccccc}
\hline & $\begin{array}{c}K \\
\left(\mathrm{~cm} \mathrm{~min}^{-1}\right)\end{array}$ & $\begin{array}{c}S \\
\left(\mathrm{~cm} \mathrm{~min}^{-\frac{1}{2}}\right)\end{array}$ & $\begin{array}{c}i_{0} \\
(\mathrm{~cm})\end{array}$ & $\begin{array}{c}i_{i} \\
(\mathrm{~cm})\end{array}$ & $\begin{array}{c}t_{\mathrm{c}} \\
(\mathrm{min})\end{array}$ & $\begin{array}{c}\Delta \theta_{\mathrm{g}} \\
\left(\mathrm{g} \mathrm{g}^{-1}\right)\end{array}$ \\
\hline Uniform grey clay & 0.0012 & 0.125 & 1.7 & 5.6 & 185 & 0.12 \\
Red-brown earth & 0.0043 & 0.320 & 4.8 & 2.5 & 225 & $0.12(0-10 \mathrm{~cm})$ \\
& & & & & & $0.16(10-20 \mathrm{~cm})$
\end{tabular}

(e) Parameters derived by trial and error from equations (4) and (5) for $x / q$ experimental values of flume experiments with restriction on air escape:

\begin{tabular}{ccccc}
\hline & $\begin{array}{c}K \\
\left(\mathrm{~cm} \mathrm{~min}^{-1}\right)\end{array}$ & $\begin{array}{c}S \\
\left(\mathrm{~cm} \mathrm{~min}^{-\frac{1}{2}}\right)\end{array}$ & $\begin{array}{c}i_{0} \\
(\mathrm{~cm})\end{array}$ & $\begin{array}{c}t_{\mathrm{c}} \\
(\mathrm{min})\end{array}$ \\
\hline G150 sand & 0.19 & 0.95 & 4.5 & 22.4 \\
Kraznozem & 0.24 & 2.00 & 6.2 & 9.6 \\
\hline
\end{tabular}

irregularities, the value varied from $0.5 \mathrm{~cm}$ to $8 \mathrm{~cm}$, for both soils, with an average value of $4 \mathrm{~cm}$.

(ii) Indirectly by subtracting both the water which had entered the soil by graphical integration of $i\left(t_{s}\right)$ with distance $\left(x_{s}\right)$ along the bay for the whole period of advance 
and recession, plus the water drained from the lower end of the bay from the total water that entered the bay. $c$ by this method was $3.8 \mathrm{~cm}$ for the grey clay and $4 \mathrm{~cm}$ for the red-brown reath.

Table 2 summarizes the particle size analyses and the properties of all materials used in this study; the red-brown earth has a duplex profile, while the cracking grey clay has uniform texture with depth.

It proved difficult to pack the G150 sand to the same density in both column and flume. The sand in the flume, having a lower bulk density, had consequently a higher $K$ than in the column; there was no appreciable effect on $S$. The $K$ and $i_{0}$ results in Table 1 for G150 sand were obtained from observing the advance of wetting front and moisture content changes in the flume for the seven experiments where there was no impedence to air escape.

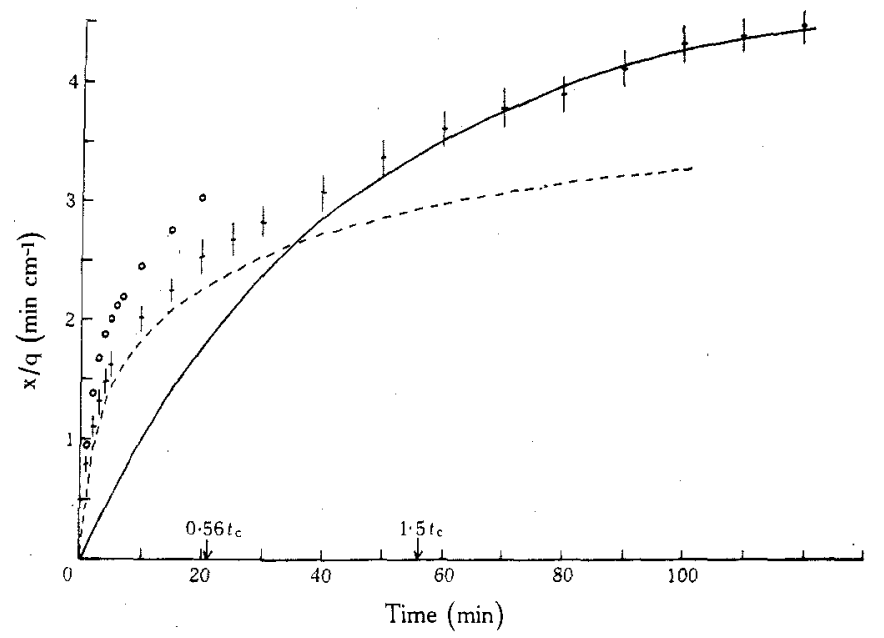

Fig. 1. $x / q v$. time for G150 sand. Average $(-)$ and standard deviation (vertical bars) for runs $1-7$. - Theoretical curve for long-term equation (5); - - - theoretical curve for short-term equation (4); o experimental results for G150 sand with restriction on air escape for runs 8-9.

\section{Results}

\section{Flume Experiments}

The advance equations under test (4), (5) and (6) are arranged in terms of $x / q$. For G150 and the kraznozem runs $1-13, i_{i}=0$. Hence all flume runs of the G150 sand (nine runs) can be considered collectively in Fig. 1 since the soil parameters are unchanged. Similarly the kraznozem (four runs) results are grouped in Fig. 2.

For both these materials, the dominant experimental variable was $q$, such that a fourfold change in $q$ caused the time taken to advance over the length of the flume to vary from $3 \frac{1}{2} \mathrm{~min}$ to $120 \mathrm{~min}$. Returning the results as $x / q$ has effectively produced two grouped sets of results for each of these uniform materials. The second major variable was the restriction on the escape of air vertically through the base of the profile in addition to air escaping horizontally in the direction of the advancing front. The monitored changes in air pressure were small as a consequence of sealing the base and the sampling ports. The effect of the restriction was to increase air pressures (cm water) from $2 \mathrm{~cm}$ to $4.4 \mathrm{~cm}$ for $\mathrm{G} 150$, and from $0.1 \mathrm{~cm}$ to $0.4 \mathrm{~cm}$ for the kraznozem, when the wetting front was just above the manometer at 35 and $50 \mathrm{~cm}$ below the surface. However, the effect is marked and both materials behave as if sorptivity has decreased. By contrast, changes in $q$ have produced no effect in 
$x / q$ with time for these materials-the changes in $c$ are threefold, but as $c$ is always a small number in the flume experiments relative to $S$ (or $i_{0}$ ), $\gamma$ of equation (4) although varying threefold is always small, and equations (4) and (5) support the observation that for these materials the effect of $c$ on $x / q$ would not be discernable.

Similarly a decrease of slope causes an increase in $c$ but has little effect on $x / q$ for these materials. Inaccuracy in estimation of $c$ was unimportant for the calculations involving equations (4) and (5).

Photographs of the shape of the wetting front show that for the G150 sand there is a hydrophobic effect such that the sand beneath the surface at the advance front was wetting slightly in advance of the immediate surface layer. Therefore the vertical infiltration implied in the Lewis-Milne equation does not occur at the immediate advance front. In independent experiments, it was observed that wetting of the sand with a fine 'mist' spray removed hydrophobic effects such as beads of water rolling over a steeply sloping layer of sand. Hence in run 5 the immediate surface layer was prewetted with a fine spray. The advance results in terms of $x / q$ were indistinguishable from those for the non-wetted runs, although the thickness $c$ was less than in the comparable run 2 .

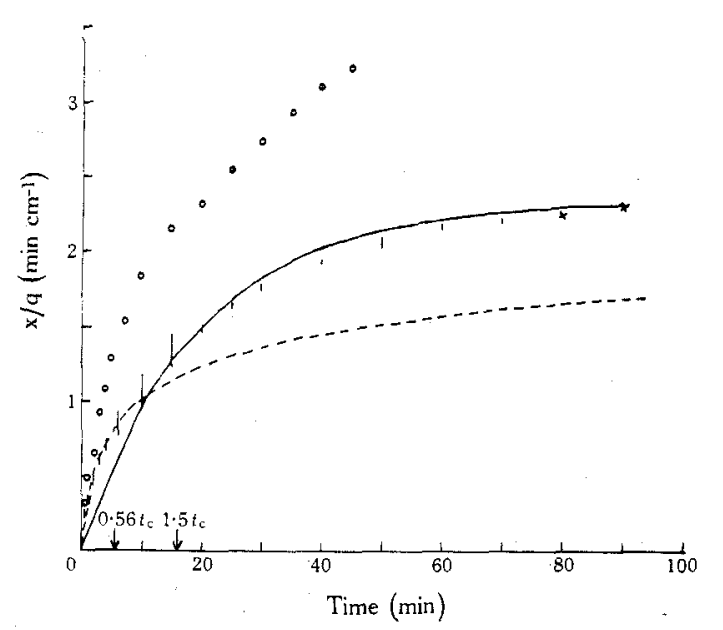

Fig. 2. $x / q$ versus time for kraznozem sample. Average (-) and standard deviation (vertical bars) for runs 10-12. $\times$ Non-replicated results, run 10 ; __ and - - as in Fig. 1; O experimental results with restriction on air escape for run 13 .

The theoretical $x / q v, t$ relationships calculated from equations (4) and (5) using the parameters of Table 2 are superimposed in Figs 1 and 2. A programmable desk calculator was used with the rational approximation of erc $\eta$ given by Abramowitz and Stegun (1968, equation 7.1.26) for (4). The Lewis-Milne equation used in conjunction with (2) gives a satisfactory match at low times, whereas at large times equation (5) is more satisfactory, as was observed earlier for uniform materials (Collis-George 1974). Using the derived quantity $t_{\mathrm{c}}$ (Collis-George 1974) where $t_{\mathrm{c}}$ is the time at which $S \sqrt{ } t_{\mathrm{c}}=i_{0}$, the short-term equation (4) applies to approximately $0 \cdot 5 t_{\mathrm{c}}$, whereas the long-term equation (5) applies beyond $1.0 t_{\mathrm{c}}$.

However, the results and predicted curves for G150 at short time are not in such good agreement as those for the kraznozem, and this will be discussed later.

For the layered systems, two differences from the uniform profiles were obvious:

Firstly, most of the parameters in Table 2 which refer to the upper layer were of little consequence to the advance behaviour. The only values used were the change in moisture content, $\Delta \theta$, and the depth of the layer, to derive the 'immediate' storage 
term $i_{i}$. This approximation is a consequence of the time scale for the coarse overlying materials being small compared with that for the underlying layer $\left(t_{\mathrm{c}}\right.$ for $\mathrm{G} 1=1.9 \mathrm{~min}$; $t_{\mathrm{c}}$ for $\mathrm{G} 150=37 \mathrm{~min}$ ). The effect of the coarse layer was to increase the effective overhead ponding, $c$, from a few millimetres to several centimetres, depending only on the thickness of the coarse sand. The calculated value of $i_{i}$ was introduced into equations (4) and (5). The experimental results in terms of $x / q$ for two thicknesses of coarse sand are given in Fig. 3; for comparison the mean experimental results for $c=2 \mathrm{~mm}$ from Fig. 1 are included. $\dagger$ Fig. 3 includes curves calculated from the Lewis-Milne equation derived from equations (4) and (5). $\alpha^{*}, \beta^{*}$ of equation (4) are imaginary so that Table $7 \cdot 9$ of Abramowitz and Stegun (1968) was used, as outlined by Philip and Farrell (1964). (Values of $\tau$ were too large for the expansion for small $\tau$ to be used.)

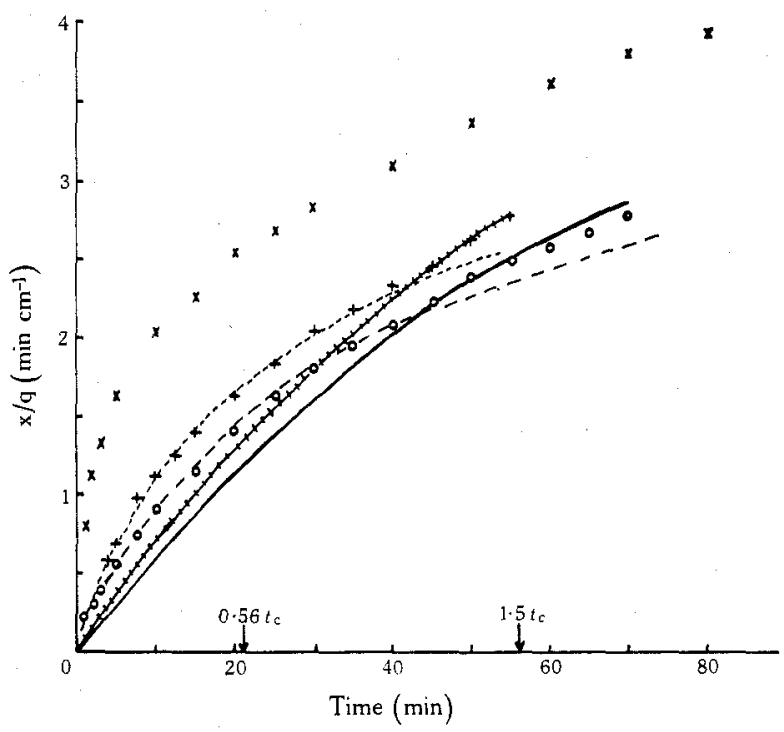

Fig. 3. $x / q$ versus time for layers of $\mathrm{G} 1$ sand superimposed on $\mathrm{G} 150$ sand.

O Run $14,15 \mathrm{~cm}$

$\mathrm{G} 1$ sand, $i_{i}=6 \mathrm{~cm}$;

$+\operatorname{run} 15,10 \mathrm{~cm}$

$\mathrm{G} 1$ sand, $i_{l}=4 \mathrm{~cm}$ :

\section{- Theoretical curve} for long-term equation (5), run 14 ;

- - - theoretical curve for short-term equation (4), run 14 ;

++++ theoretical curve for long-term equation (5), run 15 ;

- - - - theoretical curve for short-term equation (4), run 15.

$\times$ Mean result of runs $1-7, i_{i} \equiv 0 \mathrm{~cm}$.

Secondly, the infiltration pattern as observed through the Perspex walls showed that the assumption implicit in equations (2) and (3), that water entering the soil moves vertically, was untrue after infiltration advance had persisted for less than 10 min. Outlines of the wetting front are presented in Fig. 4. These suggest that once the infiltration rate of the lower layer is exceeded by the hydraulic conductivity of the upper layer, a readjustment of potentials occurs such that a perched water table develops above the interface at the upstream or entry end of the irrigation bay. This 'free' water can now provide both a vertical and a horizontal supply along the interface. This has the effect of causing the advance front to move more quickly along the interface than the simple theory of (1) allows. Practically, however, the effect is not great for these materials, and the volumes of water involved in this interfacial lateral flow, as observed through the walls of the flume, although increasing with time, are small compared with total cumulative supply as is shown in Fig. 4, so that the error in estimation of $x / q$ using the Lewis-Milne equation is small.

$\uparrow$ A referee has commented that in these experiments where coarse sand lies above fine sand there is a possibility that the value of $S$ used in (2a) and listed in Table 1(b) should be corrected to allow for the head of water ponded in the coarse sand, since the fine sand was originally characterized with a value of $c$ of $2 \mathrm{~mm}$. This would increase $S$ and hence reduce $x / q$ at any time. 


\section{Field Experiments}

Cracking grey clay. The field observations and the advance predicted by the Lewis-Milne equation from equations (4), (5) and (6) using the information from the infiltrometers in Table 2 are presented in Fig. 5 in terms of $x / q$. Error bars on the experimental values indicate high variability initially, so that equation (6a) gives only approximate values of $c+i_{i}$, and of $S$ from the field data. The salient point is that $i_{i}$ is a large component $(77 \%)$ of vertical infiltration in the period of the irrigation run, $6 \cdot 6 \mathrm{~h}$. Hence the exact form of the infiltration equations (2a), (2b) or (3a) is

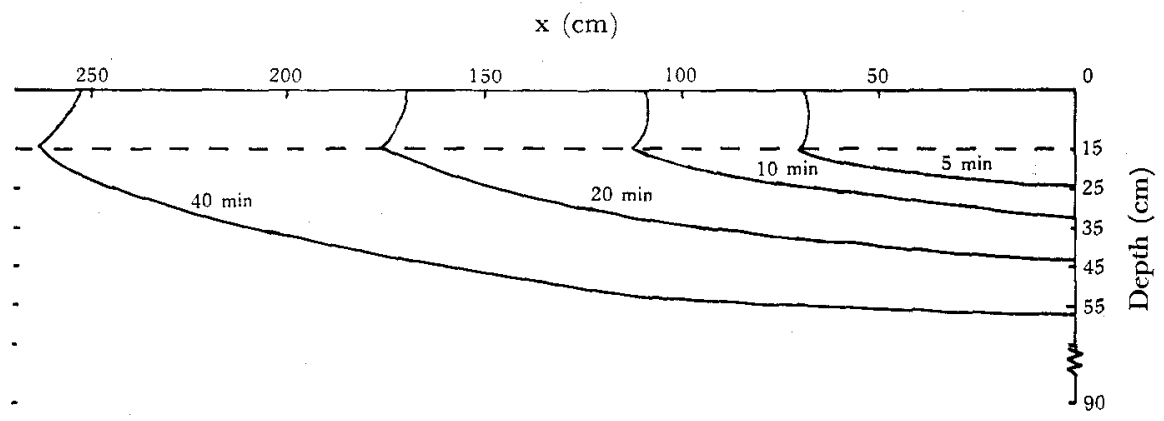

Fig. 4. Wetting front profiles for run 14 at 5, 10, 20 and 40 min. Vertical and horizontal scales $1: 10$. G1 sand $0-15 \mathrm{~cm}$ layer above $\mathrm{G} 150$ sand $15-90 \mathrm{~cm}$.

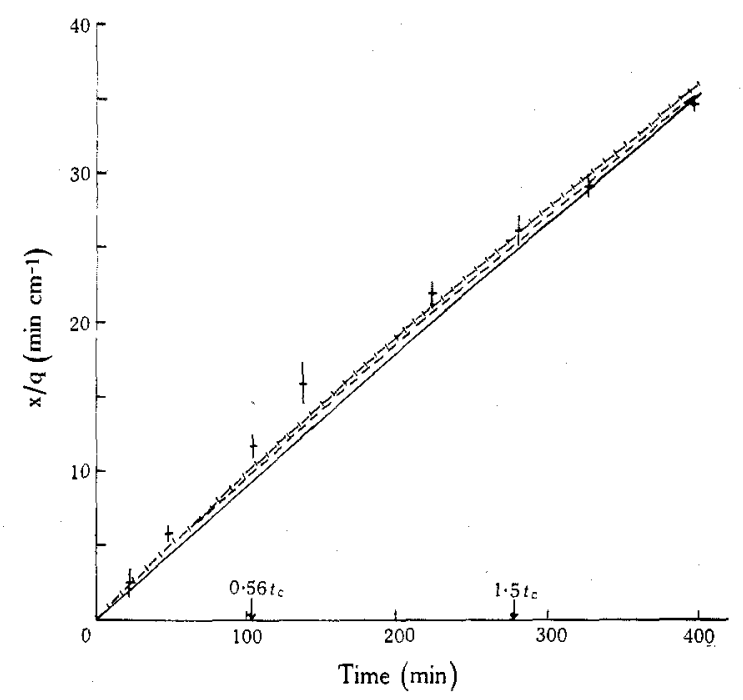

Fig. 5. $x / q$ versus time for cracking grey clay, run 16.

Average $(-)$ and standard deviation (vertical bars) of position of front measured relative to fixed pegs across width of bay; - - - and - - - as in Fig. 1;

-1-i- theoretical curve from equation (6).

largely irrelevant when the $S \sqrt{ } t$ or $K t$ terms are minor. It should be noted that, although the field run persists for $2 \cdot 1 t_{\mathrm{c}}$, by allowing $S \sqrt{ } t$ to continue to increase it compensates almost exactly for the lack of a $K t$ term at large times in equation (2b); this compensation can be regarded as merely fortuitous for particular combinations of soil parameters and length of run.

Equation (4), which is equation (47) of Philip and Farrell (1964) modified by replacing $c$ by $i_{i}+c$, provides a good match to field results. The theoretical curve was obtained by using a programmable desk calculator and the expansion of (4) 
at short times. (The Philip and Farrell (1964) equation (48) with two additional terms was used.) Use of the expansion is possible because $\left(i_{i}+c\right)$ is large, relative to $S \sqrt{ } t+K t$, and hence $\tau$ is small during the period of the irrigation run.

Red-brown earth. Due to the soil type and surface condition at the time of irrigation, the importance of the $i_{i}$ term due to quick filling cracks is smaller than in the grey clay such that by the end of the irrigation run, $396 \mathrm{~min}, i_{i}$ is $27 \%$ of the vertical infiltration at the input end of the slope, the $K t$ and $S \sqrt{ } t$ terms respectively contributing 20 and $53 \%$. The experimental scatter of $x / q$ results is much smaller than in the grey clay, and a plot of $x / q t v \cdot \sqrt{ } t$ yields $\left(c+i_{i}\right)=7.4 \mathrm{~cm}(r=-0.96)$ (the intercept equals $1 /(c+i)$ following equation (6a)). This value compares favourably with the field estimates of $c=4.0$ and $i_{i}=2.5 \mathrm{~cm}$ from infiltration experiments. Curves derived from equation (4) and (5) are presented in Fig. 6. As with the grey clay experiment, the time to complete the field runs is small (400 $\mathrm{min})$ compared with $\tau=1$.

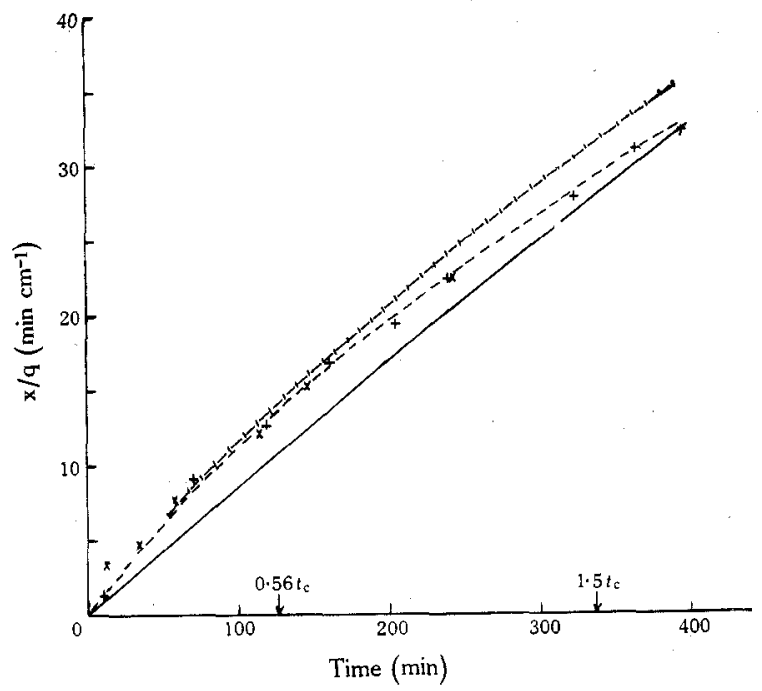

Fig. 6. $x / q$ versus time for red-brown earth runs; + average position of front measured relative to fixed pegs across width of bay for run 17; $\times$ average position for run 18 ;

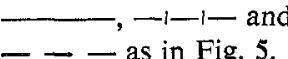

( $\tau=1$ as derived from the soil and field parameters is equivalent to $28800 \mathrm{~min}$ and $2100 \mathrm{~min}$ for the red-brown earth and grey clay respectively.) Therefore the short term expansion of (4) which avoids the use of tables can be used. By the same token, the short-term infiltration equation of Philip modified to allow for $i_{i}$, i.e. equation (2a), is the appropriate one to describe infiltration advance. The long term equation (3a) became effective for the red-brown earth only towards the end of the run $\left(1 \cdot 75 t_{\mathrm{c}}\right)$ as compared with $1 \cdot 6 t_{\mathrm{c}}$ for a total run lasting $2 \cdot 1 t_{\mathrm{c}}$ in the grey clay.

\section{Discussion}

One purpose of this paper was to stress that the use of predetermined parameters $i_{i}, i_{0}, S$, and $K$ from infiltrometers and the measurement of $c$ could completely define the infiltration advance behaviour in the field and that, if necessary, the field advance could be used to recheck $i_{i}+c$. Similarly the laboratory flume would allow checking of $i_{i}+c$ and also of $S$ and $K$. (This proved comparatively successful with a simple flume for several materials (Asseed and Kirkham 1968; Collis-George 1974.). However, in the case of the G150 sand, it proved difficult to obtain comparable densities in 
infiltration columns and in the flume. But more importantly, the G150 sand has the property of a continuously declining infiltration rate over many hours. Practically, this means that (2) only covers part of the infiltration, and that the majority of any infiltration advance run is not covered by (3) with parameters as determined by a long infiltrometer column. In this sense, this material does not confirm the original premise that predetermined parameters alone can be used. The $S$ value listed in Table 2 has been derived independently, but $K$ and $i_{0}$ values are derived from observation of the wetting front through the walls of the flume and from the change of moisture content by sampling.

Two features of the flume experiments and their analysis that need further examination to give a greater understanding of field phenomena and to make flume experiments more exact are $(a)$ the effect of temperature changes and $(b)$ the effect of small changes in $q$ (and of $c$ ) during the course of the run. In the case of the G150 sand, discontinuous movement of the front as a series of small surges over the ground surface, probably because of hydrophobic properties, was a feature of all except run 5; also the runs extended over a wide range of laboratory temperatures. Additionally, when the problem of uniformity and reproducibility of packing is considered, the degree of confidence that can be placed on the agreement of the predicted and observed $x / q$ values for the G150 sand (without a coarse sand layer) is less than had been expected when the experiments were designed.

Restriction of the escape of air vertically ahead of the wetting front and enhancement of air movement horizontally had the expected effect of reducing infiltration and increasing run-off. Although the increases in air pressure were small, they were effective in reducing infiltration. The degree of saturation as determined by direct sampling did not decrease and initially it was presumed that $K$ had not changed. However, it proved impossible using equations (4) and (5), to match the experimental results for the impeded air flow experiments in Figs 1 and 2 if any of the parameters in Table $2(b)$ were used. By trial and error using both equations (4) and (5), a new set of parameters was found. These are listed in Table 2(e). All parameters for both materials were lower in the air impedence runs. The effect of changes in this order on infiltration advance phenomena is so great, that we would suggest that the good agreement between theory and practice found to date, is largely a consequence of the air pressure regimes in the flume or field runs being identical with those in laboratory long columns and field infiltrometers-an untested specification.

The Lewis-Milne equation, which assumes exclusively vertical infiltration, has been shown to predict behaviour in good agreement with experimental results for a variety of soil systems with a wide range of soil properties, provided the appropriate infiltration equation is chosen. This agreement occurs, despite the fact that movement of water is not exclusively vertical in soil profiles which are duplex in terms of their $K$ and $S$ characteristics. Further experimentation in the laboratory and field is needed to monitor the phenomena occurring near this interface, which can be regarded as an interlayer run-off.

A feature of the work reported here is that the simple modification of short-term and long-term infiltration equations by the addition of an 'instantaneous' storage term for a cracking layer, or for a highly permeable uppermost layer with a short time constant, has extended the practical use of the Lewis-Milne equation to a large range of field soils.

In a comparison of infiltration equations (Collis-George 1977), it was observed 
that (2) gives a good match for experimental vertical infiltration data up to $0 \cdot 56 t_{c}$, whereas (3) gives a good match beyond $1 \cdot 5 t_{\mathrm{c}}$. Applying this to infiltration advance equation (4) should exactly predict irrigation advance to $0.56 t_{\mathrm{c}}$. Beyond this time, the reliability of the prediction would depend on the relative contributions of $i_{i}, K t$ and $S \sqrt{ } t$. For example in the case of G150 sand, Fig. 1 shows that at $t=t_{0}$ only one-sixth of the wetted ground surface has not been inundated for $t \leqslant 0 \cdot 56 t_{\text {c }}$ and therefore use of (2) or (2a) via (4) would overestimate $i$ and underestimate $x / q$ at $t=t_{\mathrm{c}}$. By contrast, use of the long-term equation (3) or (3a) at $t=1 \cdot 5 t_{\mathrm{c}}$ would overestimate $i$ over a large part of the inundated soil and underestimate $x / q$. At $t=2 \cdot 0 t_{\mathrm{c}}$, more than $86 \%$ of the wetted surface is at steady state and equation (5) should yield good results.

Comparison of various $t_{\mathrm{c}}$ in Table 2 with the infiltration advance results in the figures suggests that (5) can be used to give accurate results when $t>1 \cdot 5 t_{\mathrm{c}}$, but that (4) has a greater applicability than would follow from the simple analysis above, and that the greater the value of $i_{i}$ the longer (4) can be used with safety. $0 \cdot 56 t_{\mathrm{c}}$ and $1 \cdot 5 t_{\mathrm{c}}$ are marked on the figures for convenience.

Infiltration equations that cover the whole time range rather than the beginning $((2)$ and (2a)) or the end ((3) and (3a)) have been proposed (e.g. Collis-George (1977) and Philip (1969)), but their introduction into the Lewis-Milne equation has not proved practicable at present. For some materials, e.g. G150 sand, such equations would be advantageous. For others, materials such as the cracking soils considered in this paper, judicious use of equations (4), (5) and (6) describe with sufficient accuracy the behaviour of the soil under irrigation.

\section{Acknowledgments}

Financial assistance by the Water Research Foundation of Australia is gratefully acknowledged.

We are grateful to Mr R. H. Read, of the Biological and Chemical Research Institute, New South Wales Department of Agriculture, for providing access to his results for the grey clay and red-brown earth from the Trangie Research Station.

\section{References}

Abramovitz, M., and Stegun, I. A. (1968). 'Handbook of Mathematical Functions.' (Dover Publications: New York.)

Asseed, M., and Kirkham, D. (1968). Advance of irrigation water on the soil surface in relation to soil infiltration rate: a mathematical and laboratory model study. Res. Bull. Iowa Agric. Home Econ. Stn. Ames, Iowa, No. 565.

Collis-George, N. (1974). A laboratory study of infiltration advance. Soil Sci. 117, 282-7.

Collis-George, N. (1977). Infiltration equations for simple soil systems. Water Resour. Res. 13, 395-403. Lewis, M. R., and Milne, W. E. (1938). Analysis of border irrigation. Agric. Eng. 19, 267-72.

Parlange, J-Y. (1973), Note on the infiltration advance front from border irrigation. Water Resour. Res. 9, 1075-8.

Philip, J. R. (1957). The theory of infiltration: 5. The influence of the initial moisture content. Soil Sci. 84, 329-39.

Philip, J. R. (1969). Theory of infiltration. Adv. Hydrosci. 5, 215-96.

Philip, J. R., and Farrell, D. A. (1964). General solution of the infiltration problem on irrigation hydraulics. J. Geophys. Res. 69, 621-31.

Sakkas, J. G., and Strelkoff, T. (1974). Hydrodynamics of surface irrigation advance phase. J. Irrig. Drain. Div. Proc. Am. Soc. Civ. Eng. 100, 31-48. 